\title{
Clinical Pharmacology of Sildenafil in Infants and Children
}

Gian Maria Pacifici

Associate Professor of Pharmacology, via Sant’Andrea 32, 56127 Pisa, Italy.

Corresponding Author: Gian Maria Pacifici, Associate Professor of Pharmacology, via Sant'Andrea 32, 56127 Pisa, Italy.

Received Date: August 27, 2021; Accepted Date: September 23, 2021; Published Date: October 08, 2021

Citation: Gian M. Pacifici (2021) Clinical pharmacology of sildenafil in infants and children. J Pharmaceutics and Pharmacology Research 4(4), DOI: $10.31579 / 2693-7247 / 045$

Copyright: (c) Gian Maria Pacifici, This is an open access article distributed under the Creative Commons Attribution License, which permits unrestricted use, distribution, and reproduction in any medium, provided the original work is properly cited.

\begin{abstract}
Sildenafil is a competitive and selective inhibitor of phosphodiesterase 5. Sildenafil is cleared by hepatic CYP3A (major route) and CYP2C9 (minor route) and concomitant administration of potent CYP3A inducers (e.g., bosentan) causes decreases in plasma levels of sildenafil. CYP3A4 inhibitors (erythromycin and cimetidine) inhibit sildenafil metabolism prolonging the half-life and elevating blood levels of sildenafil. Sildenafil is a pulmonary arterial vasodilator and it has been used in the treatment of persistent pulmonary hypertension. The initial oral dose is 250 to $500 \mu \mathrm{g} / \mathrm{kg} 4$ times-daily in infants and the oral dose is 10 to $20 \mathrm{mg}$ thrice-daily in children with a body-weight up to $20 \mathrm{~kg}$ or $>20 \mathrm{~kg}$, respectively. Sildenafil has been found efficacy and safe in infants and children but it may induce adverse-effects. Following an oral dosing, the absorption rate constant is $0.343 \mathrm{~h}^{-1}$, and the elimination half-life is 2.41 hours in children suggesting that sildenafil is rapidly absorbed and eliminated. The interaction of sildenafil with drugs and the metabolism of sildenafil have been extensively studied. The principal routes of sildenafil metabolism are: $\mathrm{N}$-demethylation, oxidation, and aliphatic dihydroxylation, and the major metabolite is $\mathrm{N}$-desmethyl sildenafil. The treatment of infants and children with sildenafil has been extensively studied. Sildenafil citrate and sildenafil cross the human placenta and sildenafil migrates into the breast-milk in significant amounts. The aim of this study is to review the sildenafil dosing, efficacy and safety, effects, adverse-effects, pharmacokinetics, interaction with drugs, metabolism, treatments, and sildenafil placental transfer and migration into the breast-milk.
\end{abstract}

Key words: sildenafil, dosing, efficacy and safety, effects, adverse-effects, pharmacokinetics, drug-interaction, metabolism, treatment, placenta, breast-milk, infants, children

Running title: Sildenafil in infants and children

\section{Introduction}

\section{Mechanism of action of sildenafil}

Sildenafil, which structurally mimics the purine ring of cGMP, is a competitive and selective inhibitor of phosphodiesterase 5. Sildenafil has a relatively high selectivity ( $>1,000$-fold) for human phosphodiesterase 5 over other phosphodiesterases. By inhibiting cGMP hydrolysis, sildenafil elevates cellular levels of cGMP and augments signalling through the cGMP-protein kinase G pathway, provided guanylyl cyclase is active [1].

\section{Administration distribution metabolism and excretion of sildenafil}

Sildenafil is rapidly absorbed and reaches a peak plasma concentration 1 hour after oral administration. Sildenafil is cleared by hepatic CYP3A (major route) and CYP2C9 (minor route). Sildenafil and its major active metabolite, $\mathrm{N}$-desmethyl sildenafil, have terminal half-lives of about 4 hours in adults. Both the parent compound and the major metabolite are highly bound to plasma protein $(96 \%)$. Metabolites are predominantly excreted into the faeces ( 73 to $88 \%$ ) and to a lesser extent into the urine; non-metabolised sildenafil is not detected in urines or faeces. The clearance is reduced in elderly (> 65 years), leading to an increase in the AUC values for the parent drug and the N-desmethyl metabolite [1].

\section{Clinical use and adverse-effects of sildenafil}

Sildenafil, 5 to $20 \mathrm{mg}$ thrice-daily improves exercise capacity, functional class, and hemodynamics. In addition, improved exercise capacity and hemodynamic parameters, sildenafil (initiated at $20 \mathrm{mg}$ thrice-daily, titrated to 40 to $80 \mathrm{mg}$ thrice-daily) plus long-term epoprostenol therapy also resulted in delayed time to clinical worsening of PAH in clinical studies. Dose adjustment for reduced renal and hepatic function is usually not necessary except for severe hepatic and renal impairment. Concomitant administration of potent CYP3A inducers (e.g., bosentan) will generally cause substantial decreases in plasma levels of sildenafil. The mean reduction in the bioavailability of sildenafil $(80 \mathrm{mg}$ thricedaily) when co-administered with epoprostenol was 28\%. CYP3A4 inhibitors (e.g., protease inhibitors used in HIV therapy, erythromycin and cimetidine) inhibit sildenafil metabolism, thereby prolonging the half-life and elevating blood levels of sildenafil. Consistent with its mechanism of action, potentiation of cGMP signalling, sildenafil and other phosphodiesterase 5 inhibitors potentiate the hypotensive effects of 
nitrate vasodilators, producing dangerously low blood pressure. Thus, the administration of phosphodiesterase 5 inhibitors to patients receiving organic nitrates is contraindicated. In any event, the patient's undergoing cardiovascular status and concurrent use of hypotensive agents (e.g., nitrate vasodilators, $\alpha$ adrenergic antagonists) must be considered prior to use of this class of drugs. Headache (16\%) and flushing (10\%) are the most frequently reported adverse-effects. Patients taking sildenafil or vardenafil may notice a transient blue-green tinting of vision due to inhibition of retinal phosphodiesterase 6, which is involved in phototransduction [1]. Sildenafil is used as a pulmonary artery vasodilator in infants and children with primary post-surgical pulmonary hypertension. It is also being used to treat persistent pulmonary hypertension of the newborn infant, and to wean them from inhaled nitric oxide treatment [2]. Sildenafil is used for the treatment of persistent pulmonary hypertension, and the retinal vascularity must be established before sildenafil is used in extremely preterm infants. Sildenafil is contraindicated in infants taking organic nitrates in any form and in infants with a known hypersensibility to sildenafil. The monitoring of blood pressure and oxygenation should be continuously performed [3].

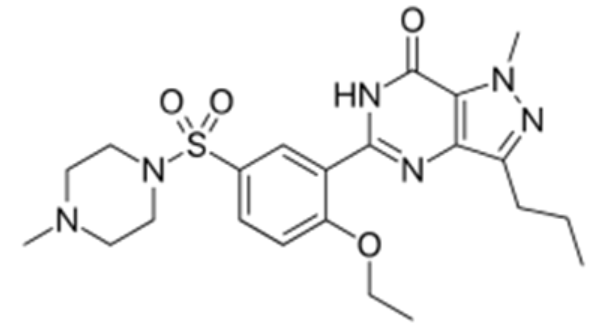

Sildenafil molecular structure $($ molecular weight $=474.6$ grams $/$ mole $)$

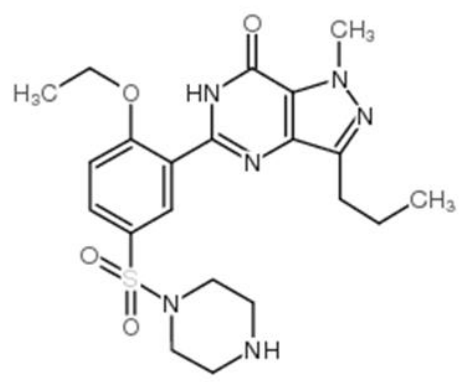

$\mathrm{N}$-Desmethyl sildenafil molecular structure (molecular weight $=460.6$ grams/mole)

\section{Literature search}

The literature search was performed electronically using PubMed database as search engine and the following key words were used: "sildenafil dosing infants, children", sildenafil efficacy, safety infants, children", "sildenafil effects infants, children, "sildenafil adverse-effects infants, children", "sildenafil pharmacokinetics infants, children", "sildenafil drug interactions", "sildenafil metabolism", "sildenafil treatment infants, children", "sildenafil placental transfer", and "sildenafil migration into the breast-milk". In addition, the books: The Pharmacological Basis of Therapeutics [1], Neonatal Formulary [2], NEOFAX $^{\circledR}$ by Young and Mangum [3], and The British National Formulary for Children [4] are consulted.

\section{Results}

\section{Administration schedules of sildenafil to infants and children}

Oral treatment to infants [2]. Start by giving 250 to $500 \mu \mathrm{g} / \mathrm{kg} 4$ timesdaily and increase the dose as required, to no more than $2 \mathrm{mg} / \mathrm{kg}$ thricedaily. Start with a low dose if there is hepatic or renal impairment. There are a few reports of infants who respond benefiting from substantial oral treatment for some weeks or months. Intravenous treatment to infants [2]. The usual dose is $100 \mu \mathrm{g} / \mathrm{kg}$ as a continuous infusion. Occasionally an infusion rate of $200 \mu \mathrm{g} / \mathrm{kg} / \mathrm{hour}$ is required. Loading dose of up to 200 $\mu \mathrm{g} / \mathrm{kg}$ given over $30 \mathrm{~min}$ has been used but can cause profound hypotension. Oral treatment of pulmonary arterial hypertension (initiated under specialist supervision) [4]

Children aged 1 to 11 months. Give initially 250 to $500 \mu \mathrm{g} / \mathrm{kg} 6$ times-daily to thrice-daily. Adjust the dose according to the response, and start with the lower dose and frequency, especially if used with other vasodilators; the maximum dose $=30 \mathrm{mg}$ daily.

Children aged 1 to 17 years with a body-weight of $20 \mathrm{~kg}$. Give: $10 \mathrm{mg}$ thrice-daily.

Children aged 1 to 17 years with body-weight of $20 \mathrm{~kg}$ and above. Give: $20 \mathrm{mg}$ thrice-daily.

Dose adjustments due to interactions [4]

The manufactures advise to reduce the dose with concurrent use of moderate and potent inhibitors of CYP3A4 (avoid treatment with ketoconazole, itraconazole, and ritonavir) no specific recommendation made for children. Contra-indications to sildenafil treatment [4]. Hereditary degenerative retinal disorders, history of non-arthritic anterior ischaemic optic neuropathy, recent history of stroke, and sickle-cell anaemia.

Cautions for sildenafil treatment [4]

Active peptic ulcerations, anatomical deformation of the penis, autonomic dysfunction, blending disorders, cardiovascular disease, hypotension (avoid if severe), intravascular volume depletion, left ventricular outflow obstruction, ocular disorders, predisposition to priapism, and pulmonary veno-occlusive disease.

\section{Efficacy and safety of sildenafil in infants and children}

There is currently no evidence of serious adverse-effects in infants exposed to sildenafil. Sildenafil remains a valuable option for the treatment of pulmonary hypertension in young infants [5]. Sildenafil used for treatment of pulmonary hypertension has potential for reducing mortality-rate and improving oxygenation in infants, especially in resource-limited settings where inhaled nitric oxide is not available [6]. Oral sildenafil is a safe, simple, and effective treatment for persistent pulmonary hypertension in newborn infants [7]. Sildenafil treatment for 16 weeks has no effect on pulmonary vascular resistance index or mean pulmonary arterial pressure in children with Down syndrome and pulmonary arterial hypertension. Children with Down syndrome may be less responsive to sildenafil for pulmonary arterial hypertension [8]. Oral sildenafil is a safe and effective alternate for persistent pulmonary hypertension following congenital heart surgery in children [9]. Medium term Sildenafil therapy improves oxyhaemoglobin saturations and exercise tolerance in children with pulmonary hypertension without any adverse-effects [10]. Safety data suggest that sildenafil is well tolerated among children with idiopathic pulmonary arterial hypertension and pulmonary arterial hypertension associated with congenital heart disease [11].

\section{Effects of sildenafil in infants and children}

Sildenafil is associated with increasing foetal weight at birth [12]. Treatment of newborn infants with intravenous sildenafil, during the first day of life, is associated with acute improvement in oxygenation in more than $40 \%$ of infants [13]. Treatment with sildenafil provides a dosedependent recovery of neonatal retinal function and structure [14]. Oral sildenafil is administered easily and tolerated as well as placebo and improves oxygenation index in infants with severe persistent pulmonary hypertension [15]. Sildenafil reduces N-terminal pro b-type natriuretic peptide levels in all infants with bronchopulmonary dysplasia-associated pulmonary hypertension [16]. The use of perioperative sildenafil in children has a statistically significant reduction in the mean pulmonary 
artery pressure without any adverse-effects [17]. Intravenous sildenafil is as effective as inhaled nitric oxide and causes pulmonary vasodilator in children with congenital heart disease [18].

\section{Common or very common adverse-effects in infants and children [4]}

Alopecia, anaemia, anxiety, cough, diarrhoea, dizziness, fluid retention, gastrointestinal discomfort, headaches, increased risk of infections, insomnia, nasal complains, nausea, night sweats, pain, skin reactions, tremor, vasodilatation, and vision disorders.

\section{Uncommon adverse-effect in infants and children [4]}

Arrhythmias, chest pain, drowsiness, dry eye, dry mouth, eye discomfort, eye disorders, eye inflammation, fatigue, feeling hot, gynecomastia, haemorrhage, hypertension, hypotension, myalgia, numbness, palpitations, sinus congestion, tinnitus, vertigo, and vomiting.

\section{Rare or very rare adverse-effects in infants and children [4]}

Acute coronary syndrome, arteriosclerotic retinopathy, cerebrospinal insufficiency, glaucoma, haematospermia, hearing impairment, irritability, optic neuropathy (discontinue treatment if sudden visual impairment occurs), oral hypaesthesia, priapism, retinal occlusion, scleral discolouration, seizure, severe cutaneous adverse reactions, sudden cardiac death, syncope, and throat tightness.

\section{Pharmacokinetics of sildenafil in infants}

den Otter et al. [19] studied the pharmacokinetics of sildenafil in 23 newborn infants, aged 0.3 to 0.9 days, with congenital diaphragmatic hernia and pulmonary hypertension who were treated with sildenafil loading dose of $0.35 \mathrm{mg} / \mathrm{kg}$ (IQR $0.16 \mathrm{mg} / \mathrm{kg}$ ) for 3 hours, followed by a continuous infusion of $1.5 \mathrm{mg} / \mathrm{kg}$ daily (IQR $0.1 \mathrm{mg} / \mathrm{kg}$ daily). All infants received inotropic drug support and were treated with inhaled nitric oxide.

\begin{tabular}{|c|c|c|c|}
\hline Parameter & Base model & Final model (RSE 1\%) & Bootstrap results Median $(95 \% \mathrm{CI})$ \\
\hline Objective function value & 1191 & 1160 & $1,154(918-1,372)$ \\
\hline TBC of sildenafil $(\mathrm{L} / \mathrm{h})$ & 6.7 & $5.2(19)$ & $5.1(3.7-7.0)$ \\
\hline Age (days) & --- & $0.58(26)$ & $0.58(0.3-0.9)$ \\
\hline Vc of sildenafil $(\mathrm{L})$ & 75.1 & $115(30)$ & $118(61-159)$ \\
\hline Vp of sildenafil (L) & 10.0 & 10.0 (na) & NA \\
\hline $\mathrm{Q}$ of sildenafil $(\mathrm{L} / \mathrm{h})$ & 44.3 & $221(3)$ & $330(1.9-13,719)$ \\
\hline TBC of metabolite $(\mathrm{L} / \mathrm{h})$ & 24.0 & $25.9(12)$ & $26.6(21.2-32.6)$ \\
\hline $\mathrm{V}$ of metabolite & 1,040 & $366(83 \%)$ & $287(79-999)$ \\
\hline \multicolumn{4}{|l|}{ Interindividual variation (\%) } \\
\hline TBC of sildenafil & 50.3 & $51.3(24 \%)$ & $24(5-65)$ \\
\hline Vc of sildenafil & 32.2 & $21.0(55 \%)$ & $5(0-35)$ \\
\hline TBC of metabolite & 37.8 & $40.5(25 \%)$ & $15(2-5)$ \\
\hline \multicolumn{4}{|l|}{ Residual variability } \\
\hline Proportional TBC of sildenafil & 0.60 & $0.50(10)$ & $0.5(0.4-0.6)$ \\
\hline Proportional metabolite & 0.57 & $0.44(10)$ & $0.4(0.5-0.5)$ \\
\hline
\end{tabular}

$\mathrm{TBC}=$ total body clearance. $\mathrm{RSE}=$ relative standard error. $\mathrm{Vc}=$ central distribution volume. $\mathrm{Vp}=$ peripheral distribution volume. Metabolite $=\mathrm{N}-$ desmethyl sildenafil. IIV $=$ interindividual variability. TBC $=$ TBL (sildenafil)*(weight in $\mathrm{kg} / 70) * * 0.75 * \mathrm{EXO}(\mathrm{IIV}$ sildenafil)*(2.4)**0.58. Shrinkage: Base model TBC sildenafil 12\%. TBC metabolite 26\%, Vc 61\%; final model TBC $11 \%$. Vc 59\%. TBC metabolite $19 \%$.

Table 1. Pharmacokinetic parameter estimates of the base model, final model, and bootstrap analysis, by den Otter et al. [19].

This table shows that Vc of sildenafil is greater than Vp of sildenafil, the total body clearance of the metabolite is greater than that of sildenafil, and there is a remarkable interindividual of the pharmacokinetic parameters.

Gonzalez et al. [20] investigated the pharmacokinetics of sildenafil in 34 premature infants with mean postmenstrual, postnatal ages of 125 days (range, 7 to 279), 41.6 weeks (range, 26.0 to 62.7), respectively, and weighing $3.41 \mathrm{~kg}$ (range, 0.59 to 8.1 ). Sildenafil was administered enterally at a dose of $2.79 \mathrm{mg} / \mathrm{kg}$ daily (range, 0.13 to 8.38 ).

\begin{tabular}{|c|c|c|c|c|}
\hline \multirow{2}{*}{ Parameter ${ }^{\mathrm{b}}$} & \multirow[b]{2}{*}{ Estimate (\%RSE) } & \multicolumn{3}{|c|}{ Bootstrap $(\mathrm{N}=1,000)^{\mathrm{a}}$} \\
\hline & & $2.5^{\text {th }}$ Percentile & Median & $97.5^{\text {th }}$ Percentile \\
\hline \multicolumn{5}{|l|}{ Structurally model and covariate effect parameters } \\
\hline $\mathrm{Ka}\left(\mathrm{h}^{-1}\right)$ & $1.59(88.1 \%)$ & 0.27 & 1.09 & 4.52 \\
\hline FSil (\%) & $0.29(33.0 \%)$ & 0.19 & 0.31 & 0.86 \\
\hline $\mathrm{TBC}(\mathrm{L} / \mathrm{h} / 70 \mathrm{~kg})$ & $27.8(51.4 \%)$ & 10.6 & 35.5 & 323 \\
\hline DV Sil,C (L/70 kg) & $116(16.1 \%)$ & 28.5 & 96.2 & 146 \\
\hline DVSil,P (L/70 kg) & $28.1(20.4 \%)$ & 17.2 & 34.1 & 182 \\
\hline Ka, DMS $\left(h^{-1}\right)$ & $1.3(49.4 \%)$ & 0.42 & 1.00 & 2.97 \\
\hline TVF, DMS & $1.29(46.6 \%)$ & 0.55 & 1.42 & 11.59 \\
\hline TBCDMS/Fmet, DMS (L/70 kg) & $135(62.4 \%)$ & 49.1 & 178 & 1,363 \\
\hline DVDMS/Fmet, DMS (L/70 kg) & $1,670(22.2 \%)$ & 1,029 & 1,808 & 2,819 \\
\hline $\mathrm{Q}(\mathrm{L} / \mathrm{h} / 70 \mathrm{~kg})$ & $1.67(74.3 \%)$ & 0.65 & 3.30 & 40.94 \\
\hline Percentage TBC reduction with fluconazole use (\%) & $58.9(19.1 \%)$ & 31.2 & 61.7 & 76.20 \\
\hline 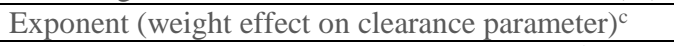 & $0.96(12.5 \%)$ & 0.75 & 1.03 & 1.48 \\
\hline \multicolumn{5}{|l|}{ Interindividual variability (reported as $\% \mathrm{CV})^{\mathrm{d}}$} \\
\hline TBC & $33.3(45.5 \%)$ & 11.9 & 32.2 & 49.9 \\
\hline DVSil,C & $26.8(98.6 \%)$ & 0.27 & 24.1 & 73.9 \\
\hline
\end{tabular}




\begin{tabular}{|l|l|l|l|l|}
\hline TBCDMS/F met, DMS & $56.5(27.3 \%)$ & 37.0 & 55.3 & 73.8 \\
\hline DVSil,C & $48.1(48.1 \%)$ & 0.48 & 43.2 & 73.2 \\
\hline Residual error (reported as \%CV) ${ }^{\mathrm{e}}$ & $45.6(24.2 \%)$ & 32.7 & 45.0 & 54.6 \\
\hline Proportional error for sildenafil (\%) & $40.7(19.0 \%)$ & & 40.8 & 49.2 \\
\hline Proportional error for DMS (\%) & $0.12^{\mathrm{f}}(26.4 \%)$ & 0.07 & 0.13 & 0.20 \\
\hline Covariance
\end{tabular}

$\mathrm{TBC}=$ total body clearance. $\mathrm{DV}=$ distribution volume. Sil $=$ sildenafil. DMS = N-desmethyl sildenafil. RSE = relative standard error $($ expressed as a percentage) $\mathrm{Ka}=$ sildenafil first-order absorption rate constant. Fsil = Sildenafil bioavailability. TBC = Sildenafil total body clearance $($ assuming complete conversion to $\mathrm{N}$-desmethyl sildenafil). DVSil,C = sildenafil central compartment distribution volume. DVsil,P $=$ sildenafil peripheral compartment distribution volume. Ka, DMS $=\mathrm{N}$-desmethyl sildenafil first-order absorption rate constant. TVF, DMS $=$ typical value for the bioavailability of N-desmethyl sildenafil. TBCDMS/Fmet, DMS = N-desmethyl sildenafil total body clearance. DVMDS/F met, DMS = N-desmethyl sildenafil distribution volume. $\mathrm{Q}=$ inter compartmental clearance for Sildenafil.

Table 2. Final population pharmacokinetic model parameter estimates, by Gonzalez et al. [20].

${ }^{a} 83.4 \%$ of bootstrap runs resulted in a successful minimization. ${ }^{b} \mathrm{Ka}\left(\mathrm{h}^{-1}\right)$ $=1.59$. FSil $=0.29$. TBC $(\mathrm{L} / \mathrm{h})=27.8 *\left(\mathrm{WT}_{\mathrm{i}} / 70 \mathrm{~kg}\right)^{0.96 *}(0.411[$ if infant received fluconazole])*exp(ni,DVSSil,C). DVSil,P $(\mathrm{L})=28.1 *\left(\mathrm{WT}_{\mathrm{i}} / 70\right.$ $\mathrm{kg})$. Ka,DMS $\left(\mathrm{h}^{-1}\right)=1.3$. FDMS $*(1-F S i l)$ TBCDMS/Fmet,DMS $(\mathrm{L} / \mathrm{h})=$

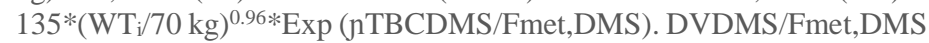
$(\mathrm{L})=1,670 *\left(\mathrm{WT}_{\mathrm{i}} / 70 \mathrm{~kg} / * \operatorname{Exp}(\mathrm{n} \mathrm{DVDMS} / \mathrm{Fmet}, \mathrm{DMS})\right.$. And Q $(\mathrm{L} * / \mathrm{h})=$ $1.67 *\left(\mathrm{WT}_{\mathrm{i}}\right.$ is the individual participant body-weight.

'The same exponent is assumed for all Sil and DMS total body clearance parameters. The exponent for the weight effect on the distribution volume parameter is fixed to $1 .{ }^{\mathrm{d}} \mathrm{ETA}$ shrinhage $(\%) . \mathrm{TBC}=10.5 \%$. DVSil,C $=$ $48.0 \%$. TBCDMS/Fmet,DMS $=6.43 \%$. DVDMS/Fmet,DMS $=38.2 \%$. ${ }^{\mathrm{e}} \mathrm{EPS}$ shrinkage $(\%)$ : Sil: $117 \%$. DMS $=12.0 \%$. ${ }^{\mathrm{f}}$ Correlation coefficient $=$ 0.65 .

This table shows that sildenafil is rapidly absorbed following enterally dosing, the central distribution volume is larger than the peripheral distribution volume, the absorption rate of the N-desmethyl sildenafil is similar to that of sildenafil, the total body clearance and the distribution volume of $\mathrm{N}$-desmethyl sildenafil are greater than those of sildenafil, and there is a remarkable interindividual variability of the pharmacokinetic parameters. Such variability is accounted by the wide range of the postmenstrual, postnatal ages, and body-weight values.

\section{Pharmacokinetics of sildenafil in children}

Oya et al. [21] studied the pharmacokinetics of sildenafil in 13 children with a postnatal age, body-weight, and body-surface of $382+345$ days, $6.67+2.52 \mathrm{~kg}$, and $0.340+0.094 \mathrm{~m}^{2}$, respectively, who underwent cardiac surgery for congenital heart disease. Sildenafil was administered orally at a dose of $0.5 \mathrm{mg} / \mathrm{kg} 4$ times-daily.

\begin{tabular}{|c|c|c|c|}
\hline & \multirow{2}{*}{$\begin{array}{l}\text { Children with rapid absorption of } \\
\text { sildenafil }(\mathrm{N}=4)\end{array}$} & \multirow{2}{*}{$\begin{array}{l}\text { Children with reduced or delayed absorption of } \\
\text { sildenafil }(\mathrm{N}=9)\end{array}$} \\
\hline Parameter & & & \\
\hline \multicolumn{2}{|l|}{ Postnatal age (day) } & $215+283$ & $460+323$ \\
\hline & Drug & & \\
\hline \multirow[b]{2}{*}{ Peak conc. (ng/ml) } & Sildenafil & $67.9+26.1$ & $19.1+6.5^{*}$ \\
\hline & $\begin{array}{l}\text { N-desmethyl } \\
\text { sildenafil }\end{array}$ & $43.3+26.9$ & $27.2+14.6$ \\
\hline \multirow[b]{2}{*}{$\mathrm{AUC}_{0-6 \mathrm{~h}}(\mathrm{ng} * \mathrm{~h} / \mathrm{ml})$} & Sildenafil & $160+47$ & $53.5+21.3^{*}$ \\
\hline & $\begin{array}{l}\text { N-desmethyl } \\
\text { sildenafil }\end{array}$ & $112+60$ & $65.7+32.2^{*}$ \\
\hline \multicolumn{2}{|l|}{ Sild/DMS ratio } & $4.08+4.85$ & $1.82 *$ \\
\hline
\end{tabular}

Table 3. Pharmacokinetic parameters of sildenafil and N-desmethyl sildenafil which are obtained in 13 children with or without rapid absorption of sildenafil. Figures are the mean+ SD, by Oya et al. [21].

Sil = sildenafil. DMS = N-desmethyl sildenafil. $*$ P-value $<0.05$.

This table shows that children with rapidly absorption of sildenafil have higher peak concentration and AUC than children reduced are delayed adsorption of sildenafil.
Olguín et al. [22] investigated the pharmacokinetics of sildenafil in 12 children with pulmonary arterial hypertension aged $11.1+4.8$ years (range, 1.4 to15.0) and weighing $14.0+1.5 \mathrm{~kg}$ (range, 7.5 to 26.0). Sildenafil was administered orally at a dose of $1 \mathrm{mg} / \mathrm{kg}$ once-daily.

\begin{tabular}{|l|l|}
\hline Parameter & Results \\
\hline Absorption rate constant $\left(\mathrm{h}^{-1}\right)$ & 0.343 \\
\hline Elimination rate constant $\left(\mathrm{h}^{-1}\right)$ & 0.35 \\
\hline Elimination half-life $(\mathrm{h})$ & $2.41+1.18$ \\
\hline Distribution volume $(\mathrm{L})$ & $20.1+14.5$ \\
\hline Total body clearance $(\mathrm{L} / \mathrm{h})$ & $5.85+2.81$ \\
\hline Time to reach peak plasma concentration $(\mathrm{h})$ & $0.92+0.30$ \\
\hline Peak plasma concentration $(\mathrm{ng} / \mathrm{ml})$ & $366+179$ \\
\hline Area under the plasma concentration versus time & $2,062+638$ \\
\hline
\end{tabular}

Table 4. Pharmacokinetic parameters of sildenafil which are obtained in 12 children with pulmonary arterial hypertension, Figures are the mean+SD, by Olguín et al. [22]. 
This table shows that sildenafil is rapidly absorbed following oral dosing, is rapidly eliminated, and the distribution volume is larger than the water volume.

\section{Interaction of sildenafil with drugs}

When sildenafil is given in combination with fluconazole resulted in a geometric mean ratio of 1.01 for simulated AUCss,0-24 relative to virtual infants receiving sildenafil alone and the. Thus the sildenafil dose should be reduced by $60 \%$ [23]. Lesinurad (200 mg once-daily) is an inducer of CYP3A and affects sildenafil exposure. Sildenafil exposure decreases by approximately by $34 \%$ the peak concentration and AUC when administered with multiple-dose of lesinurad $200 \mathrm{mg}$ [24]. Exposure of sildenafil increases in presence of boceprevir. A dose adjustment of sildenafil is therefore necessary and an initial dose of $25 \mathrm{mg}$ of sildenafil is suggested [25]. In men with angina, the blood pressure is reduced when sildenafil is co-administered with glyceryl trinitrate for $\geq 8$ hours [26]. Sildenafil exposure is increased in the presence of darunavir/ritonavir and a dose adjustment of sildenafil is warranted when is co-administered with darunavir/ritonavir [28]. Both saquinavir and ritonavir modify the pharmacokinetics of sildenafil presumably through inhibition of CYP3A4 and the more pronounced effect of ritonavir may be attributed to its potent inhibition of CYP2C9 [29]. The co-administration of ciprofloxacin and clarithromycin significantly increases sildenafil bioavailability due to the inhibitory effect of ciprofloxacin and clarithromycin on CYP3A4 [30]. Co-administration of sildenafil with isosorbide mononitrate or glyceryl trinitrate significantly reduces blood pressure than isosorbide mononitrate or glyceryl trinitrate alone and sildenafil should not be administered to patients taking nitrates [31]. Plasma sildenafil AUC is markedly increased in the presence of indinavir compared with controls [32].

\section{Metabolism of sildenafil}

The CYP3A4, and to a lesser extent CYP2C9, mediate metabolism of sildenafil into $\mathrm{N}$-desmethyl sildenafil [33]. The relative contributions to net intrinsic clearance of sildenafil are $79 \%$ for CYP3A4, $20 \%$ for CYP2C9; and < 2\% for CYP2C19 and CYP2D6 [34]. CYP2C9 and CYP3A4 are the enzymes that metabolize sildenafil [35]. CYP3A5 and CYP3A4 play a significant role in the metabolism of phosphodiesterase inhibitors including sildenafil [36]. The metabolite formation-rate of phosphodiesterase type- 5 is inhibited by sildenafil and tadalafil via CYP3A4, CYP3A5, and CYP3A7 isoforms [37]. The pharmacokinetics of radiolabelled $\left[{ }^{14} \mathrm{C}\right]$-sildenafil are consistent with rapid absorption, firstpass metabolism and the principal routes of sildenafil metabolism are: Ndemethylation, oxidation, and aliphatic dihydroxylation [38].

\section{Treatment of infants and children with sildenafil}

Bronchopulmonary dysplasia is the most common complication in preterm infants and often is complicated by pulmonary hypertension and sildenafil is used to treat these diseases [39]. Sildenafil is used in treating pulmonary hypertension associated with lung and renal hypoplasia in infants with congenital diaphragmatic [40]. The low cost, the oral availability, and the good tolerability of sildenafil make it a suitable and simple alternative therapy for secondary pulmonary hypertension including persistent postoperative pulmonary hypertension associated with ventricular septal defect [41]. Sildenafil continues to be the major treatment option for paediatric pulmonary arterial hypertension in infants and children [42]. Pulmonary arterial hypertension is a life-threatening disease and sildenafil is one of the therapeutic agents used extensively in the treatment of pulmonary arterial hypertension in infants and children [43]. Pulmonary arterial hypertension contributes to disability and death in children and the treatment with sildenafil has been approval by the European Medicines Agency for its paediatric use in Europe and in the U.S. by the Food and Drug Administration [44]. Oral sildenafil given in low doses controls pulmonary hypertension safely and effectively in children undergoing operations to correct congenital heart defects [45]. A single dose of sildenafil prevents rebound after withdrawal of nitric oxide and reduces the duration of mechanical ventilation in children [46]. Sildenafil therapy reduces the mortality-rate of pulmonary arterial hypertension in children [47].

\section{Transfer of sildenafil across the human placenta}

Of the 150 participants administered sildenafil citrate, 33 post-treatment maternal samples and 26 cord blood samples were obtained. The interval between sildenafil citrate administration and maternal blood sampling was 2.5 hours (range, 1.9 to 3.2 ) and the interval between last dose of sildenafil citrate and cord blood sampling was 5.6 hors (range, 3.5 to 6.7). Sildenafil citrate crosses the human placenta in significant amounts [48]. At steady state, the foetal-to-maternal transfer ratio of sildenafil is $0.37+0.03$ in healthy placentas versus 0.66 and 0.47 in the 2 preeclampic placentas [49]. Transfer clearance of sildenafil in the high dose, during the first hour of perfusion, is $3.15 \mathrm{ml} / \mathrm{min}$ (range, 2.14 to $3.19 \mathrm{ml} / \mathrm{min}$ ) for the maximum tolerated concentration and $3.07 \mathrm{ml} / \mathrm{min}$ (range, 2.75 to $3.42 \mathrm{ml} / \mathrm{min}$ ) for the therapeutic concentration (not significant). The foetus-to-maternal concentration ratio significantly increases over time, up to $0.91+0.16$ for the maximal concentration and $0.95+0.22$ for the therapeutic concentration at the end of the perfusion (not significant). Sildenafil crosses the term placenta at a relatively high rate ex-vivo, which suggests that there is sufficient placental transfer to reach clinically active foetal drug levels at the currently used maternal doses [50].

\section{Migration of sildenafil into the breast-milk}

The concentrations of sildenafil and its major metabolite N-desmethyl sildenafil are measured in three breast-milk samples. The concentration of sildenafil ranges from 1.64 to $4.49 \mathrm{ng} / \mathrm{ml}$ and that of N-desmethyl sildenafil ranges from 1.18 to $1.82 \mathrm{ng} / \mathrm{ml}$ in the breast-milk [51].

\section{Discussion}

Sildenafil, which structurally mimics the purine ring of cGMP, is a competitive and selective inhibitor of phosphodiesterase 5. By inhibiting cGMP hydrolysis, sildenafil elevates cellular levels of cGMP and augments signalling through the cGMP-protein kinase G pathway, provided guanylyl cyclase is active. Sildenafil is rapidly absorbed following oral dosing and it is cleared by hepatic CYP3A4 (major route) and by CYP2C9 (minor route) and the major metabolite is N-desmethyl sildenafil which is predominately excreted into the faeces. Concomitant administration of potent CYP3A inducers (e.g., bosentan) causes decrease in plasma levels of sildenafil and the co-administration of sildenafil with CYP3A4 inhibitors (e.g., erythromycin and cimetidine) inhibits sildenafil metabolism prolonging the half-life and elevating blood levels of sildenafil [1]. Sildenafil is a pulmonary artery vasodilator [2] and it is used to treat persistent pulmonary hypotension [3]. Sildenafil is contraindicated in infants taking organic nitrates and in infants with a known hypersensitivity to sildenafil [3]. Sildenafil may be administered orally; the oral treatment consists in 250 to $500 \mu \mathrm{g} / \mathrm{kg} 4$ times-daily in infants [2]. In children, the oral dosage of sildenafil varies with the child age and body-weight and it is 10 or $20 \mathrm{mg}$ thrice-daily in children with a body-weight up to $20 \mathrm{~kg}$ or $>20 \mathrm{~kg}$, respectively [4]. Sildenafil has been found efficacy and safe in infants and children [5-11]. Sildenafil is used in the treatment of pulmonary hypertension and does not induce serious adverse-effect in infants [5], and sildenafil reduces the mortality-rate in infants with pulmonary hypertension [6]. Oral sildenafil is safe and effective in the treatment of persistent pulmonary hypertension in newborn infants [7]. Children with Down syndrome may be less responsive to sildenafil for pulmonary arterial hypertension [8]. Oral sildenafil is safe and effective for persistent pulmonary hypertension in children [9], and sildenafil improves oxyhaemoglobin saturation and exercise tolerance in children with pulmonary hypertension [10]. Sildenafil is well tolerated in children with idiopathic pulmonary arterial hypertension [11]. The effects of sildenafil have reported in infants and 
children [12-18]. Sildenafil increases foetal body-weight at birth [12] and intravenous sildenafil improves oxygenation in infants [13]. Treatment with sildenafil recovers neonatal retinal function and structure and these effects are dose dependent [14]. Oral sildenafil improves oxygenation index in infants with severe persistent pulmonary hypertension [15]. Sildenafil reduces $\mathrm{N}$-terminal pro b-type natriuretic peptide levels in infants with bronchopulmonary dysplasia-associated to pulmonary hypertension [16], and sildenafil reduces the pulmonary artery pressure in children [17]. Intravenous sildenafil is as effective as inhaled nitric oxide in children with pulmonary vasodilator and with congenital heart diseases [18]. Sildenafil induces various adverse-effects which are classified as: common or very common, uncommon, or rare or very rare [4]. The pharmacokinetics of sildenafil and its metabolite $\mathrm{N}$-desmethyl sildenafil have been studied by Otter et al. [19], Gonzalez et al. [20], Oya et al. [21], and by Olguin et al. [22]. The absorption rate constant, the total body clearance, and the central and peripheral distribution volumes rage in a wide interval. Following oral administration, the absorption rate constant is $0.343 \mathrm{~h}^{-1}$, the elimination half-life is 2.41 hours, and the time to reach peak plasma concentration is 0.92 hours suggesting that sildenafil is rapidly absorbed and eliminated [22]. The central distribution volume is larger than the peripheral distribution volume $[19,20]$. The total body clearance and the distribution volume of $\mathrm{N}$-desmethyl sildenafil are higher than those of sildenafil. The higher total body clearance of $\mathrm{N}$ desmethyl sildenafil suggests that this metabolite is cleared more rapidly than sildenafil [20]. Following oral administration of sildenafil, the peak plasma concentration and the AUC of sildenafil are greater in children with rapid absorption than in children with reduced or delayed absorption of sildenafil [21]. Sildenafil interacts with drugs [23-32]. When sildenafil is co-administered with fluconazole, the sildenafil dose should be reduced [23]. Lesinurad is an inducer of CYP3A and decreases sildenafil exposure [24], and boceprevir increases the exposure of sildenafil [24]. Sildenafil combined with glyceryl trinitrate reduces the blood pressure [25]. Darunavir/ritonavir [28] and saquinavir/ritonavir [29] modify the sildenafil pharmacokinetics being inhibitors of CYP3A4 and CYP2C9, respectively. The co-administration of ciprofloxacin and clarithromycin with sildenafil increases the bioavailability of sildenafil due to the inhibitory effect of CYP3A4 [30], the combination of sildenafil with isosorbide mononitrate or glyceryl trinitrate decreases the blood pressure [31], and indinavir increases the plasma AUC of sildenafil [32]. The CYP3A4, and to a lesser extent CYP2C9, mediate the metabolism of sildenafil into $\mathrm{N}$-desmethyl sildenafil $[33,35]$. The relative contributions to the intrinsic clearance of sildenafil are $79 \%$ for CYP3A4, $20 \%$ for CYP2C9, and $<2 \%$ for CYP2C19 and CYP2D6 [34]. CYP3A5 and CYP3A4 metabolize phosphodiesterase inhibitors including sildenafil [36], and sildenafil and tadalafil are metabolised by CYP3A4, CYP3A5, and CYP3A7 [37]. The principal metabolic routes of sildenafil are: Ndemethylation, oxidation, and aliphatic dihydroxylation [38]. The treatment of infants and children with sildenafil has been extensively studied [39-47]. Sildenafil treats bronchopulmonary dysplasia which is often complicated by pulmonary hypertension in preterm infants [39]. Sildenafil is the recommended drug to treat pulmonary arterial hypertension [40-45]. A single dose of sildenafil prevents rebound after withdrawal of nitric oxide and reduces the duration of mechanical ventilation in children [46], and sildenafil reduces the mortality-rate of pulmonary arterial hypertension in children [47]. The transfer of sildenafil citrate across the human placenta has been studied in-vivo [48] and the transfer of sildenafil has been studied in-vitro using the placenta perfusion $[49,50]$. Sildenafil citrate and sildenafil cross the placenta in significant amounts and the foetal-to maternal transfer ratio of sildenafil is 0.37 [49] and 0.95 [50]. In literature there is only one study on the migration of sildenafil into the breast-milk and it has been reported by Wollein et al. [51]. The concentration of sildenafil in the breast-milk ranges from 1.64 to $4.49 \mathrm{ng} / \mathrm{ml}$ and that of $\mathrm{N}$-desmethyl sildenafil ranges from 1.18 to 1.82 $\mathrm{ng} / \mathrm{ml}$.
In conclusion, sildenafil, which structurally mimics the purine ring of cGMP, is a competitive and selecting inhibitor of phosphodiesterase 5. By inhibiting cGMP hydrolysis, sildenafil elevates cellular levels of cGMP and augments signalling through the cGMP-protein kinase G pathway, provided guanylyl cyclase is active. Sildenafil may be administered orally and following oral dosing it is rapidly absorbed. Sildenafil is cleared by hepatic CYP3A (major route) and CYP2C) (minor route) and the major metabolite of sildenafil is N-desmethyl sildenafil. Concomitant administration of CYP3A inducers (e.g., bosentan) causes decrease in plasma concentration of sildenafil. CYP3A4 inhibitors (e.g., protease inhibitors used in HIV therapy, erythromycin and cimetidine) inhibit sildenafil metabolism, prolonging the half-life and elevating blood concentration of sildenafil. Sildenafil is used as a pulmonary artery vasodilator and in the treatment of persistent pulmonary hypertension. The initial oral dosage of sildenafil consists in 250 to $500 \mu \mathrm{g} / \mathrm{kg} 4$ timesdaily in infants. In children, the oral dosage of sildenafil varies with the child age and with the body-weight and is 10 or $20 \mathrm{mg}$ thrice-daily in children with a body-weight up to 20 or $>20 \mathrm{~kg}$, respectively. Sildenafil has been found efficacy and safe in infants and children but it may cause averse-effects. The effects of sildenafil have been extensively studied. Following oral dosing of sildenafil, sildenafil is rapidly absorbed and eliminated; the absorption rate constant is $0.343 \mathrm{~h}^{-1}$ and the elimination half-life is 2.41 hours. The total body clearance and the central and peripheral distribution volumes range in a wide interval in infants and children. Sildenafil interacts with drugs and the treatment of infants and children with sildenafil has been extensively studied. Sildenafil citrate and sildenafil cross the human placenta and sildenafil migrates into the breast-milk in significant amounts. The aim of this study is to review the clinical pharmacology of sildenafil in infants and children.

\section{Conflict of interests}

The authors declare no conflicts of financial interest in any product or service mentioned in the manuscript, including grants, equipment, medications, employments, gifts, and honoraria.

This article is a review and drugs have not been administered to men or animals.

\section{Acknowledgments}

The author thanks Dr. Patrizia Ciucci and Dr. Francesco Varricchio, of the Medical Library of the University of Pisa, for retrieving the scientific literature.

\section{References}

1. Fraidenburg DR, Desai AA, Yuan XJ (2018). "Treatment of pulmonary Arterial Hypertension”. In The Goodman \& Gilman's. The Pharmacological Basis of the Therapeutics, Brunton Hilaldandan LL, Knollmann BC, editors. Mc Graw Hill, 13th Edition, USA, New York. pp: 573-584.

2. Neonatal Formulary. "Sildenafil": Oxford University Press. 8th Edition, Great Clarendon Street, Oxford, OX2, 6DP, UK. 2020; pp: 721-724.

3. Young TE, Mangum B (2010). NEOFAX ${ }^{\circledR}$. "Sildenafill". Thomas Reuters Clinical Editorial Staff, 23rd Edition, Montvale, USA. pp: 198-199.

4. The British national formulary for children. "Sildenafil". Macmillan, 78th Edition, Hampshire International Business Park, Hampshire, Lime Three Way, Basingstoke, Hampshire, UK. 2019-2020; pp: 122-123.

5. Samiee-Zafarghandy S, Smith PB, van den Anker JN (2014). Safety of sildenafil in infants. Pediatr Crit Care Med. 15(4): 362368.

6. Kelly LE, Ohlsson A, Shah PS (2017). Sildenafil for pulmonary hypertension in neonates. Cochrane Database Syst Rev. 8(8): CD005494. 
7. Kumar JRV, Settv NHS, Javaranganath M, Maniunath CN (2021). Efficacy, safety, and tolerability of bosentan as an adjuvant to sildenafil and sildenafil alone in persistant pulmonary hypertension (PPHN), Int Med Appl Sci. 11(4): 2016-220.

8. Beghetti M, Rudzinski A, Zhang M. (2017) Efficacy and safety of oral sildenafil in children with Down syndrome and pulmonary hypertension. BMC Cardiovasc Disord. 17(1): 177. doi: 10.1186.

9. Nemoto S, Sasaki T, Ozawa H, Katsumata T, Kishi K, Okumura $\mathrm{K}$, et al. (2010) Oral sildenafil for persistent pulmonary hypertension early after congenital cardiac surgery in children. Eur J Cardiothorac Surg,38(1): 71-77.

10. Karatza AA, Bush A, Magee AG. (2005) Safety and efficacy of Sildenafil therapy in children with pulmonary hypertension, Int $J$ Cardiol. 100(2): 267-273.

11. Huddleston AJ, Knoderer CA, Morris JL, Ebenroth ES. (2009) Sildenafil for the treatment of pulmonary hypertension in pediatric patient, Pediatr Cardiol. 30(7): 871-882.

12. da Silva Ferreira RD, Negrini R, Bernardo WM, Simões R, Piato S. (2019) The effects of sildenafil in maternal and fetal outcomes in pregnancy: A systematic review and meta analysis, PLoS One. 14(7): e0219732.

13. Kipfmueller F, Schroeder L, Berg C, Heindel K, Bartmann P, Mueller A. (2018) Continuous intravenous sildenafil as an early treatment in neonates with congenital diaphragmatic hernia, Pediatr Pulmonol. 53(4): 452-460.

14. Jung S, Johnstone A, Khoja Z, Rampakakis E, Lachapelle P, Wintermark P. (2016) Sildenafil Improves Functional and Structural Outcome of Retinal Injury Following Term Neonatal Hypoxia-Ischemia, Invest Ophthalmol Vis Sci. 57(10): 43064314.

15. Baquero H, Soliz A, Neira F, Venegas ME, Sola A. (2006) Oral sildenafil in infants with persistent pulmonary hypertension of the newborn: a pilot randomized blinded study. Pediatrics, 117(4): 1077-1083.

16. Qasim A, Dasgupta S, Aly AM, Jain SK.(2018) Sildenafil Use in the Treatment of Bronchopulmonary Dysplasia-Associated Pulmonary Hypertension: A Case Series, AJP Rep. 8(4): e219e222.

17. Bhasin S, Gogia P, Nair R, Sahoo TK. (2017) Perioperative sildenafil therapy for children with ventricular septal defects and associated pulmonary hypertension undergoing corrective surgery: A randomised clinical trial, Indian J Anaesth. 61(10): 798-802.

18. Schulze-Neick I, Hartenstein P, Li J, Stiller B, Nagdyman N, Hübler M, et al. (2003) Intravenous sildenafil is a potent pulmonary vasodilator in children with congenital heart disease. Circulation,108 (Suppl 1): 167-173.

19. den Otter SCMC, Kipfmueller F, Winter BCM, Allegaert K, Tibboel D, Mueller A, et al. (2020) Pharmacokinetic modeling of intravenous sildenafil in newborns with congenital diaphragmatic hernia, Eur J Clin Pharmacol. 76(2): 219-227.

20. Gonzalez D, Laughon MM, Smith PB, Ge S, Ambalavanan N, Atz A, et al. (2019) Population pharmacokinetics of sildenafil in extremely premature infants, Br J Clin Pharmacol. 85(12): 28242837.

21. Oya Y, Watahiki D, Matsunaga M, Hirono K, Ichida F, Aoki M, et al. (2020) The Pharmacokinetics of Sildenafil May Be Affected by Intestinal Absorption Rate in Children Admitted to the Intensive Care Unit, Biol Pharm Bull. 43(12): 1917-1923.

22. Olguín HJ, Martínez HO, Pérez CF, Mendiola BR, Espinosa LR, Pach, et al. (2017) Pharmacokinetics of sildenafil in children with pulmonary arterial hypertension. World J Pediatr.; 13(6): 588592.
23. Salerno SN, Edginton A, Gerhart JG, Laughon MW, Ambalavanan N, Sokol GM, et al.( 2021) Physiologically-Based Pharmacokinetic Modeling Characterizes the CYP3A-Mediated Drug-Drug Interaction Between Fluconazole and Sildenafil in Infants, Clin Pharmacol Ther. 109(1): 253-262.

24. Gillen M, Yang CY, Wilson D, Valdez S, Lee C, Kerr B, et al. (2017) Evaluation of Pharmacokinetic Interactions Between Lesinurad, a New Selective Urate Reabsorption Inhibitor, and CYP Enzyme Substrates Sildenafil, Amlodipine, Tolbutamide, and Repaglinide, Clin Pharmacol Drug Dev. 6(4): 363-376.

25. Mora-Peris B, Else L, Goldmeier D, Mears A, Weston R, Cooke G, et al. (2015) A Phase I study to assess the safety, tolerability and pharmacokinetic profile of boceprevir and sildenafil when dosed separately and together, in healthy male volunteers, $J$ Antimicrob Chemother. 70(6): 1812-1815.

26. Oliver JJ, Kerr DM, Webb DJ. (2009) Time-dependent interactions of the hypotensive effects of sildenafil citrate and sublingual glyceryl trinitrate, Br J Clin Pharmacol. 67(4): 403412.

27. Burgess G, Hoogkamer H, Collings L, Dingemanse J. (2008) Mutual pharmacokinetic interactions between steady-state bosentan and sildenafil, Eur J Clin Pharmacol. 64(1): 43-50.

28. Sekar V, Lefebvre E, De Marez T, Pauw MD, Paepe ED, Vangeneugden T, et al.( 2008) Effect of repeated doses of darunavir plus low-dose ritonavir on the pharmacokinetics of sildenafil in healthy male subjects: phase I randomized, openlabel, two-way crossover study. Clin Drug Investig,28(8): 479485.

29. Muirhead GJ, Wulff MB, Fielding A, Kleinermans D, Buss N. (2000) Pharmacokinetic interactions between sildenafil and saquinavir/ritonavir. Br J Clin Pharmacol. 50(2): 99-107.

30. Hedaya MA, El-Afify DR, El-Maghraby GM. (2006) The effect of ciprofloxacin and clarithromycin on sildenafil oral bioavailability in human volunteers, Biopharm Drug Dispos. 27(2): 103-110.

31. Webb DJ, Muirhead GJ, Wulff M, Sutton JA, Levi R, Dinsmore WW. (2000) Sildenafil citrate potentiates the hypotensive effects of nitric oxide donor drugs in male patients with stable angina, $J$ Am Coll Cardiol. 36(1): 25-31.

32. Merry C, Barry MG, Ryan M, Tjia JF, Hennessy M, Eagling, et al. (1999) Interaction of sildenafil and indinavir when coadministered to HIV-positive patients. AIDS. 13(15): F101-F107.

33. Hyland R, Roe EG, Jones BC, Smith DA. (2001) Identification of the cytochrome P450 enzymes involved in the N-demethylation of sildenafil, Br J Clin Pharmacol. 51(3): 239-248.

34. Warrington JS, Shader RI, Moltke LL, Greenblatt DJ. (2000) In vitro biotransformation of sildenafil (Viagra): identification of human cytochromes and potential drug interactions, Drug Metab Dispos. 28(4): 392-397.

35. Tang P-F, Zheng X, Hu X-X, Yang C-C, Chen Z, Qian J-C, et al.(2020) Functional Measurement of CYP2C9 and CYP3A4 Allelic Polymorphism on Sildenafil Metabolism, Drug Des Devel Ther. 14: 5129-5141.

36. Ku H-Y, Ahn H-J, Seo K-A, Kim H, Oh M, Bae SK, et al. (2008) The contributions of cytochromes P450 3A4 and 3A5 to the metabolism of the phosphodiesterase type 5 inhibitors sildenafil, udenafil, and vardenafil , Drug Metab Dispos. 36(6): 986-990.

37. Takahiro R, Nakamura S, Kohno H, Yoshimura N, Nakamura T, Ozawa S, et al. (2015) Contribution of CYP3A isoforms to dealkylation of PDE5 inhibitors: a comparison between sildenafil $\mathrm{N}$-demethylation and tadalafil demethylenation, Biol Pharm Bull. 38(1): 58-65.

38. Muirhead GJ, Rance DJ, Walker DK, Wastall P. (2002) Comparative human pharmacokinetics and metabolism of single- 
dose oral and intravenous sildenafil, $\mathrm{Br} J$ Clin Pharmacol. 53(Suppl 1): 13S-20S.

39. van der Graaf M, LA, Helbing W, Reiss I, Etnel JRG, Bartelds B. (2019) Sildenafil for bronchopulmonary dysplasia and pulmonary hypertension: a meta-analysis, Pulm Circ. 9(3): 20. doi: 10.1177.

40. Lavie-Nevo K, Harris KC, Ting JY. (2019) Use of sildenafil in an infant with persistent pulmonary hypertension secondary to lung and renal hypoplasia - a case report, BMC Pediatr. 19(1): 416. doi: 10.1186.

41. El Midany AAH, Mostafa EA, Azab S, Hassan GA. (2013) Perioperative sildenafil therapy for pulmonary hypertension in infants undergoing congenital cardiac defect closure, Interact Cardiovasc Thorac Surg. 17(6): 963-968.

42. Simonca L, Tulloh R. (2017) Sildenafil in Infants and Children, Children (Basel). 4(7): 60. doi: 10.3390.

43. Dhariwal AK, Bavdekar SB. (2015) Sildenafil in pediatric pulmonary arterial hypertension, J Postgrad Med. 61(3): 181-192.

44. Abman SH, Kinsella JP, Rosenzweig EB, Krishnan U, Kulik T, Mullen M, et al.(2013) Implications of the U.S. Food and Drug Administration warning against the use of sildenafil for the treatment of pediatric pulmonary hypertension, Am J Respir Crit Care Med. 187(6): 572-575.

45. Palma G, Giordano R, Russolillo V, Cioffi S, Palumbo S, Mucerino M, et al. (2011) Sildenafil therapy for pulmonary hypertension before and after pediatric congenital heart surgery. Tex Heart Inst J. 38(3): 238-242.

46. Namachivayam P, Theilen U, Butt WW, Cooper SM, Daniel J Penny DJ, et al. (2006) Sildenafil prevents rebound pulmonary hypertension after withdrawal of nitric oxide in children, $A m J$ Respir Crit Care Med. 174(9): 1042-1047.

47. Zhang Q, Xu B, Lv J, Wang Z, Du J. (2020) Safety and effect of sildenafil on treating paediatric pulmonary arterial hypertension: a meta-analysis on the randomised controlled trials, Cardiol Young. 30(12): 1882-1889.

48. Turner J, Russo F, DePrest J, Kumar S. (2019) Pharmacokinetics and intrapartum placental transfer of sildenafil citrate in term pregnancies, J Paed Child Heath. 55(Suppl 1): 129-130.

49. Hitzerd E, Broekhuizen M, Colafella KMM, Glisic M, de Vries R, Koch BCP, et al. (2019) Placental effects and transfer of sildenafil in healthy and preeclamptic conditions, EBioMedicine. 45: 447455.

50. Russo FM, Conings S, Allegaert K, Van Mieghem T, Toelen J, et al. (2018) Sildenafil crosses the placenta at therapeutic levels in a dually perfused human cotyledon ,J Pharm Biomed Anal. 219(6): 619.e1-619.e10. doi: 10.1016.

51. Wollein U, Schech B, Hardt J, Schramek N. (2016) Determination and quantitation of sildenafil and its major metabolite in the breast milk of a lactating woman. Am J Obstet Gynecol. 120(2): 100-105.
This work is licensed under Creative Commons Attribution 4.0 License

To Submit Your Article Click Here: Submit Manuscript

DOI: $10.31579 / 2693-7247 / 043$
Ready to submit your research? Choose Auctores and benefit from:

$>$ fast, convenient online submission

$>$ rigorous peer review by experienced research in your field

$>$ rapid publication on acceptance

$>\quad$ authors retain copyrights

$>$ unique DOI for all articles

$>$ immediate, unrestricted online access

At Auctores, research is always in progress.

Learn more https://auctoresonline.org/journals/international-journal-ofclinical-case-reports-and-reviews 